\title{
Titulares que reafirman la ineficaz respuesta de la política europea a la migración infantil africana
}

\author{
MHCJ no 4 | Año 2013 \\ Artículo n으 (42) \\ Páginas 67 a 89 \\ mhci.es
}

María-Adoración Merino-Arribas | dory.merino@unir.net

Palabras clave

Migración infantil; legislación

europea;cayuco; patera; reagrupación

familiar; Programa de Estocolmo

\section{Curriculum}

María Adoración Merino Arribas.

Periodista y coordinadora del Grado de

Comunicación de la Universidad

Internacional de La Rioja (UNIR).

Ana Baroni Luengo. Investigadora.

Periodista y médico. Facultad de Medicina y

de Comunicación de la Universidad de La

Laguna.

\section{Resumen}

Los titulares de prensa, radio y televisión seleccionados en este artículo, que corresponden a noticias españolas del trienio 2009-2012, han sido estudiados mediante el análisis cualitativo yreafirman que los últimos documentos legislativos europeos (2010-2012) sobre la migración infantil -donde se proponen iniciativas para 'salvaguardar los derechos del niño'-no dan respuesta a lo que en Europa se considera la problemática de los menores migrantes', ni tampoco consiguen frenar las expediciones clandestinas, tal y como constatanlos testimonios de un centenar de menores africanos que han llegado en pateras o cayucos a las costas canarias en los últimos seis años.

Forma de citar este artículo en las bibliografías

María-Adoración Merino-Arribas, Ana Baroni-Luengo (2013): “Titulares que reafirman la ineficaz respuesta de la política europea a la migración infantil africana”, en Miguel Hernández Communication Journal, n4, páginas 67 a 89. Universidad Miguel Hernández, UMH (Elche-Alicante). Recuperado el de de 20

de: http:/ / mhcj.es $/$ index.php?journal=mhcj\&page $=$ article\&op $=$ view\&path $\% 5 B \% 5 D=4$ 


\title{
Titulares que reafirman la ineficaz respuesta de la política europea a la migración infantil africana
}

\author{
MHCJ no 4 | Year 2013 \\ Paper $\mathrm{n}$ 누 (42) \\ Pages 67 a 89 \\ mhcj.es
}

María-Adoración Merino-Arribas | dory.merino@unir.net

Ana Baroni-Luengo | anabaroni@yahoo.es

\section{Keywords}

Clandestine expeditions for seaway, infantile Migration, European legislation on migration, familiar regrouping, Program of Stockholm, European politics on migration.

\section{Curriculum}

María Adoración Merino Arribas. Periodista y coordinadora del Grado de Comunicación de la Universidad Internacional de La Rioja (UNIR).

Ana Baroni Luengo. Investigadora. Periodista y médico. Facultad de Medicina y de Comunicación de la Universidad de La Laguna.

\begin{abstract}
Headlines of press, radio and television selected in this article, which correspond to Spanish news about the triennium 2009-2012, have been studied by means of a qualitative analysis and reaffirm that the last European legislative documents (2010-2012) on the infantile migration - where initiatives are proposed 'to safeguard the rights of the child '-do not give answer to what in Europe is considered to be 'the problems of the least migrants'. They do not manage to brake the clandestine expeditions, as states the testimonies of a hundred of African minors who have come in boats or small Indian canoes to the Canary coasts in the last six years.
\end{abstract}

\section{How to cite this paper in bibliographies}

María-Adoración Merino-Arribas, Ana Baroni-Luengo (2013): “Titulares que reafirman la ineficaz respuesta de la política europea a la migración infantil africana”, en Miguel Hernández Communication Journal, n4, páginas 67 a 89. Universidad Miguel Hernández, UMH (Elche-Alicante). Recuperado el _ de de 20

de: http:/ / mhcj.es $/$ index.php?journal $=$ mhcj\&page $=$ article\&op $=$ view\&path $\% 5 B \% 5 \mathrm{D}=4$ 


\section{Introducción}

Este estudio analiza informaciones recogidas en la prensa (nacional e internacional) recibidas por una alerta de Google con los términos 'menores inmigrantes no acompañados' durante el trienio 2009-2012. Ante la multitud de titulares exactos, fruto de tener como fuente de las informaciones a las Agencias de noticias, en este trabajo hemos seleccionado solo las más originales, bien por ser noticias propias o porque tienen más contenido.

Al mismo tiempo, también se estudian los últimos documentos legislativos europeos sobre la migración infantil (2010-2012), además de las directrices de ACNUR para el tratamiento de los menores no acompañados, con el fin de analizar si las normativas gubernamentales van encaminadas a solucionar los problemas reales de la infancia. En este sentido, las iniciativas que se proponen en los documentos legislativos europeos para 'salvaguardar los derechos del niño'se contrastan con las informaciones aparecidas en prensa, radio y televisión sobre los menores extranjeros no acompañados que llegan a las costas españolas en expediciones clandestinas.

Teniendo en cuenta que el periodismo es la historia contada por los contemporáneos, la realidad del fenómeno migratorio con cara de niño habla, por ejemplo, de 'expulsiones de menores a Marruecos', mientras que las políticas europeas sobre la migración infantil van encaminadas "a asegurarse de que cualquier menor que necesite protección la reciba y de que, independientemente de su estatuto de inmigrante, su nacionalidad o sus orígenes, todos los menores sean tratados, en principio y ante todo, como menores"1.

No es esta la única contradicción en esta materia. En el estudio realizado para comprobar si la legislación camina al mismo paso que la realidad que viven los menores migrantes destacamos que la UE todavía considera la migración infantil desde el punto de vista de 'un control de las salidas' o que las iniciativas propuestas por Europa son inviables en África. Además, los jóvenes africanos que buscan un futuro en Europa desconocen la legislación del mundo occidental y ven fracasadas sus expectativas de trabajo. También queda de manifiesto que la prueba ósea que se aplica para determinar la edad de los que llegan en pateras o cayucos no es válida para los que proceden del continente africano.

Entre los titulares estudiados destacamos los siguientes, tantode prensa, como de radio y televisión, porque son un reflejo de la ineficaz respuesta de la política europea a la migración infantil africana:

1.- España expulsa a Marruecos de forma ilegal a dos menores

.http://www.20minutos.es/noticia/1652944/0/espana/expulsa-menores-edad/marruecos-

melilla/

${ }^{1}$ Artículo 24 de la Carta de los Derechos Fundamentales de la UE. 
2.- La policía busca recuperar en Marruecos a dos menores expulsados de España. http://politica.elpais.com/politica/2012/11/20/actualidad/1353431943_970134.html

3.- Expulsados a Marruecos dos menores subsaharianos tutelados por Melilla. http://www.cadenaser.com/sociedad/articulo/expulsados-marruecos-menoressubsaharianos-tutelados-melilla/csrcsrpor/20121119csrcsrsoc 15/Tes

4.- Regresa a Melilla en patera uno de los dos menores expulsados a Marruecos. http://www.abc.es/espana/20121214/abci-melilla-menores-201212132237.html

5.- Un niño patera de ocho años.

http://www.ideal.es/granada/v/20120312/granada/nino-patera-ocho-anos-20120312.html

6.- Llega a El Hierro una patera con 43 inmigrantes, entre ellos varios menores. http://www.elmundo.es/elmundo/2012/12/28/espana/1356651265.html

7.- Pateras de juguete.

http://www.elcorreo.com/vizcaya/20091102/pvasco-espana/pateras-juguete20091102.html

8.- De los pisos patera a los burdeles con menores.

http://identitaria.es/2012/02/07/de-los-pisos-patera-a-los-burdeles-con-menores/

9.- Rescatan una patera con 42 menores cerca de las costas de Granada.

http://www.antena3.com/noticias/sociedad/rescatan-patera-menores-cerca-costasgranada $2012030200030 . h t m l$

10.- Una patera con tres embarazadas y tres menores llega a las Alhucemas http://www.publico.es/espana/441534/una-patera-con-tres-embarazadas-y-tres-menoresllega-a-las-alhucemas

11.- España desconoce el número de menores inmigrantes solos http://www.lne.es/sociedad-cultura/2011/09/28/espana-desconoce-numero-menoresinmigrantes-solos/1135199.html

La primera conclusión de este análisis es que la normativa europea dictada para resolver la migración infantil se encuentra muy lejana de la realidad que se vive en África y no considera con profundidad suficiente las motivaciones e idiosincrasia de la población emigrante, en concreto de los jóvenes africanos mayores de 13 años. 
La última normativa europea sobre la migración infantil se ha plasmado en el Programa de Estocolmo y el Plan de acción sobre los menores no acompañados (2010-2014), que recoge buena parte de las iniciativas que se proponen en los documentos que hemos analizado en este estudio incluye:

1. Programa de Estocolmo. Plan de acción sobre los menores no acompañados (2010-2014). Versión on line íntegra, disponible en: http://eurlex.europa.eu/LexUriServ/LexUriServ.do?uri=COM:2010:0213:FIN:ES:PDF.

2. «La Política de Acogida, Repatriación y Acuerdos para la integración de los Menores Extranjeros No Acompañados». Estudio comparativo de la UE elaborado por la Red Europea de Migraciones. Mayo de 2010.

3. Documento de orientación del Parlamento Europeo sobre «El internamiento de niños en los procedimientos de control de la inmigración y de determinación de la condición de inmigrantes en los Estados miembros». Julio de 2009, disponible en http://www.libertysecurity.org/article1185.html.

4. Estudio del Parlamento Europeo sobre «Las condiciones en los centros para nacionales de terceros países (campos de internamiento y centros abiertos, como centros y zonas de tránsito), con especial atención a los servicios e instalaciones destinados a las personas con necesidades especiales, en los 25 Estados miembros de la UE». Diciembre de 2007, disponible en http://www.libertysecurity.org/IMG/pdf_eu-ep-detention-centres-report.pdf

5. «Directrices de ACNUR sobre principios y procedimientos para el tratamiento de los niños no acompañados solicitantes de asilo».

6. Directrices de protección internacional: Solicitudes de asilo de niños al amparo de los artículos 1(A)2 y 1(F) de la Convención de 1951 y/o del Protocolo de 1967 sobre el Estatuto de los Refugiados. Disponible en http://www.acnur.es/PDF/4ccac1a32 20120511115452.pdf.

7. Estudio del proyecto MIREM, financiado por la UE «Los menores marroquíes no acompañados: ¿cuál es la realidad de su retorno?». Disponible en http://www.mirem.eu/recherche/rapports/200611-mirem-rep-baba.pdf.

8. Informe de PICUM sobre «Los menores indocumentados en Europa: víctimas invisibles de las restricciones a la inmigración». Disponible en http://picum.org/picum.org/uploads/publication/Undocumented\%20Children $\% 20$ in $\% 20$ Europe $\% 20$ EN.pdf.

Los documentos estudiados reflejan que desde Europa se desea abordar "problemas tales como la protección de los menores, soluciones duraderas basadas en el interés superior del niño y la cooperación con los terceros países, así como las medidas prácticas para facilitar el retorno del elevado número de menores no acompañados que no requieren protección internacional". 
Se desprende que las iniciativas legislativas de la UE tienen como prioridad 'un control de las salidas', para evitar que jóvenes africanos dejen su zona natal para entrar en Europa.

Los titulares que informan de la expulsión desde España a Marruecos, de dos menores subsaharianos, de 14 y 17 años, provocan reacción en la sociedad. Tras el hecho, la Asociación Prodein de Melilla, comunidad que tutelaba a esos dos menores, denuncia este hecho y también que la Guardia Civil había trasladado a la gendarmería marroquí a los menores que llegaron en una patera interceptada en aguas de Melilla, sin seguir el procedimiento fronterizo establecido por España. Todavía tuvo más repercusión mediática y de protesta de organizaciones sociales porque uno de los ocupantes de esa embarcación era un menor de edad ya conocido en Melilla, de nombre Mohamed Namara, que había sido expulsado desde la ciudad autónoma a Marruecos hacía unos meses y ese incidente quedó registrado en grabaciones de vídeo que están disponibles en el medio digital Periodismo Humano.

Organizaciones como MIGREUROP en España denunciaron que estas devoluciones por parte de las autoridades españolas hacia Marruecos no son casos aislados.

Así consta en informes como APDHA "Derechos Humanos en la Frontera Sur 2013", Médicos sin Fronteras "Violencia, vulnerabilidad y migración: atrapados a las puertas de Europa" y Defensor del Pueblo español "Informe anual a la Cortes Generales 2012").

No obstante, otra de las informaciones seleccionadas en el presente estudio, que lleva por título 'Pateras de juguete' pone de manifiesto que cientos de niños magrebíes se juegan la vida cruzando El Estrecho para acabar repatriados como adultos o atrapados en las redes de prostitución. Esta información va firmada por la periodista Paula Rosas, desde Rabat.

La determinación de la edad de los menores sigue sin resolver. A pesar de que la prueba ósea que se les realiza no es válida para las personas que han nacido y se han criado en África, es la que se tiene en cuenta. Ante la situación de desconcierto generada en las comunidades españolas que de una u otra forma eran receptoras de menores no acompañados, el Defensor del Pueblo instó a los responsables gubernamentales a aplicar 'criterios más rigurosos para determinar la edad de los menores extranjeros no acompañados', respetando los derechos de los menores.

Así figura en el documento "¿Menores o adultos", presentado por la citada institución, tras comprobar que no existía un registro real de los menores extranjeros que había en España.

Sin embargo, el objetivo de la petición del Defensor del Pueblo, para contar con estadísticas fiables sobre los menores extranjeros no acompañados en España, iba encaminada al objetivo de la expulsión para aquellos que realmente fueran adultos: "La diferencia entre ser mayor o 
menor de edad es muy importante", ha advertido la Defensora del Pueblo, porque "si es menor queda bajo la tutela española pero si es mayor se le expulsa", precisa el documento.

Uno de los ejemplos más claros de que la normativa de la UE se aleja de la realidad africana es que fija la mayoría de edad en los 18 años, cuando, en otros continentes está comprendida entre los 16 y los 21 años y, concretamente en África, la mayoría de edad se alcanza a los 13 años. Responde a que un individuo se considera plenamente capaz para asumir responsabilidades. Como consecuencia, en Europa se considera un 'problema' que jóvenes africanos de 17 años, por ejemplo, salgan de su zona natal para buscar un futuro en el mundo occidental.

Sin embargo, tal y como refleja el titular de ABC, del 14 de diciembre de 2012, firmado por el periodista Luis de Vega, 'Uno de los dos menores bajo protección de las autoridades españolas que fueron expulsados a Marruecos desde Melilla en noviembre ha logrado regresar a territorio español a bordo de una patera'. Y recoge una conversación telefónica con el propio menor, de nacionalidad burkinesa y 14 años de edad, desde el centro de menores de La Purísima, donde vivía hasta que unos agentes, según su testimonio, lo pusieron en contra de su voluntad al otro lado de la verja que separa la ciudad autónoma del país magrebí. No había transcurrido ni un mes desde que fuera expulsado de España y ya se encontraba otra vez en Melilla.

Los niños africanos sueñan con Europa. Esto es lo que afirman los jóvenes africanos que han llegado en cayuco a las costas canarias. En los registros de la Comunidad Autónoma de Canarias son más de 6.000 los jóvenes africanos (de 13 a 17 años) que han sido acogidos en las islas en los primeros diez años del siglo XXI por haber arribado a las islas en embarcaciones que habían partido de África. Aseguran que desean conseguir en otro continente el futuro que no les ofrece el suyo. En muchas ocasiones, ellos son la única esperanza para sus familias.El $50 \%$ salieron de su casa con 16 años cumplidos.

En África pronto supieron que la legislación europea acoge a los extranjeros menores de 18 años como si estuvieran en desamparo, aplicando la misma normativa vigente que existe para los niños nacionales. Bastaron las primeras llamadas telefónicas a sus familias para confirmarlo. Por eso, la mayoría de los adolescentes que salen en cayucos o pateras lo hacen con el consentimiento de sus padres.

¿Cuántos menores de edad han salido de África? No hay estadísticas. ¿Cuántos han entrado en Europa? La UE responde que tampoco existen datos fiables, según se apunta en el Programa de Estocolmo y el Plan de acción sobre los menores no acompañados (2010-2014).Este es el último documento elaborado por la Comisión Europea, con el fin de preservar los derechos de los niños migrantes que salen de su país natal y entran de forma clandestina por alguna frontera europea. 
Canarias y el sur peninsular son las entradas españolas que han registrado el mayor número de embarcaciones con menores de edad. A estos puntos calientes se suman las costas italianas de Sicilia y Lampedusa, que solo en el año 2007 recibieron unas 16.000 personas, de las que, al menos 2.000 fueron recogidos como menores no acompañados ${ }^{2}$. Tanto en Italia, como en España, los menores extranjeros que acceden por una entrada clandestina no son expulsados, como sucede con los adultos. Permanecen tutelados por el gobierno mientras alcanzan la mayoría de edad. Este es un factor de atracción para realizar la peligrosa travesía por mar desde el continente africano.

'Un niño patera de ocho años' es el titular de la información recogida en un diario granadino, a cuya costa llegó una patera con 40 chavales marroquíes, entre los que figuraba uno de tan solo ocho años. Era el 12 de marzo de 2012 y todos habían nacido en la aldea de Oulad Yusuf, una zona rural de la provincia de Beni Mellal (Marruecos). Además, dijeron que otro grupo de chicos estaba preparando otra salida similar.

El centenar de testimonios de los menores extranjeros acogidos en Canarias demuestran que cada uno de ellos tiene una interesante historia a sus espaldas y desean alcanzar un buen final. Entre estas historias también salen 'desencuentros' o situaciones incomprensibles, como la que narra D. M.

Menor en España y padre de familia en África. D. M. pide seguir en el anonimato y prefiere que no se conozca su historia. Llegó en un cayuco a Tenerife en el año 2007. Su viaje fue tan traumático que solo recuerda lo que él llama los detalles más importantes: las veces que estuvo a punto de morir. No sabe exactamente el tiempo que tardó en cruzar pueblos y fronteras hasta llegar al mar donde encontró el barco que le sacó de África y le llevó a Europa.

Este africano figura en las listas de los "menores extranjeros no acompañados" que ha estado acogido y tutelado por el Gobierno canario casi doce meses. Es delgado, menudo y muy callado. Bajó del cayuco aturdido y, sin saber cómo, se encontró en el grupo de los menores de edad. Se dejó llevar. Cuando ingresó en el centro de menores y pudo entender su situación dice que luchó con la alternativa que se le planteaba en su cabeza: informar del error cometido sobre su edad (ya había cumplido los 30 años) y quedaba expuesto al peligro de la repatriación, o seguir aparentando ser menor de edad, sin poder trabajar ni enviar dinero a su familia. Optó por lo segundo.

Tardó semanas en entender las primeras palabras en español. Dice que nunca tuvo un traductor que le permitiera explicarse. A pesar de que su tarjeta provisional de permiso de residencia y trabajo indica que tiene 22 años, es una autoridad entre sus iguales, que reconocen 'a los viejos'. En realidad, D. M. nació en un país africano hace 36 años. Allí dejó a su mujer y a sus tres hijos. Partió en una de las expediciones clandestinas que prometían trabajo en Europa.

\footnotetext{
${ }^{2}$ Declaraciones realizadas en Ginebra en abril de 2008 por SimoneMoscarelli, representante legal de la Organización Internacional para la Migraciones (OIM) en Lampedusa (Italia).
} 
D. M. fue incluido en el listado de menores después de haber pasado por la prueba ósea que 'certificó' que tenía menos de 18 años. Para tener certeza de la edad de los jóvenes de los cayucos se les somete a una prueba radiológica, con los parámetros del Atlas de Greulich y Pyle, con el que se compara la radiografía del menor con estándares resultantes de un muestreo de población de países del norte de Europa. Es evidente que la población nórdica no tiene el mismo desarrollo que los habitantes de países del sur. En esta prueba se permite un margen de error de un año y medio.

Forenses de prestigio, como José Luis Prieto Carrero, del Instituto Anatómico Forense de Madrid, cuestionan la exactitud de esas pruebas y establecen además, la necesidad de una entrevista con el supuesto menor que permita establecer más variables para conocer la fecha de su nacimiento. Sin embargo, la identificación queda restringida a la radiografía de la muñeca. Si de ella resulta que es mayor de edad, se le trata como tal y se le niega el amparo de la comunidad receptora.

El caso más sangrante es el recogido por la Agencia Efe, el 13 de marzo de 2010, y reproducido en medios nacionalescon el siguiente titular: "Gestionan la situación de un menor cuya edad se calculó en 65 años en lugar de 15".

La normativa de la UE respecto a estos menores se haperfilado progresivamente. Sin embargo, siempre ha ido por detrás de los acontecimientos.

Basta con leer el Programa de Estocolmo para detectar que las medias que propone Europa $\underline{\text { son adecuadas para conseguir la educación y respeto de los derechos del niño, pero no sirven }}$ para África.

Nuevamente se pone de manifiesto que, las políticas de inmigración 'dibujadas' en Europa en el siglo XXI no contemplan la auténtica realidad africana. Esta cuestión ya fue puesta de manifiesto en 2006 por el filósofo y sociólogo francés Sami Naïr, quien cuestionó las políticas oficiales del momento y denunció la falta de una estrategia coherente por parte de la UE (Naï, S., 2006).

En 2008, la inmigración pasó a ocupar el primer problema de la sociedad, seguido del paro y la vivienda (Rodríguez Díaz, Raquel y Mena Montes, Noemí, 2008: “Opinión Pública y frames: La crisis de los cayucos"...). Sin embargo, la crisis de los cayucos o pateras suponía únicamente una pequeñísima parte de lainmigración, sólo el 1\% de los extranjeros que llegaban a España lo hacían por entradas clandestinas marítimas, mientras que más del 62\% accedían por avión o barco (INE, 2008). Estas personas llegan a España con un permiso de turista en regla, por valor de tres meses, pero lo dejan expirar sin regresar a su lugar de origen y se quedan en situación administrativa irregular, con la intención de intentar regularizarse. 
No obstante, en ese año, lafuerte presencia mediática que tuvo la llegada de inmigrantes africanos en cayucos, con imágenes dantescas de esa tragedia, hizo subir este tema en la agenda pública.

En las informaciones sobre inmigrantes, los términos utilizados para narrar la situación dramática de los africanos y su lucha por alcanzar el paraíso deOccidente estaban en un lenguaje metafórico y presentando la inmigración como problema, mediante los siguientes términos: amenaza, invasión, crisis, avalancha. Estas palabras refuerzan la idea de que la llegada de africanos en pateras o cayucos puede ser una amenaza para la sociedad, especialmente para las zonas receptoras.

Precisamente, en 2008 se recrudece la crisis económica en Europa y, aunque se reducen las llegadas clandestinas, los titulares de las informaciones sobre inmigración siguen la misma línea, incluso, relacionando la inmigración con la mala situación económica que vive el mundo occidental. Estudios recientes confirman esta tesis, como el que está disponible en:http://www.revistalatinacs.org/12SLCS/2012 actas/195 Blas.pdf.

La crisis económica explica la drástica disminución de pateras y cayucos. Pero a ello hay que sumar que en los países de África Subsahariana se ha elevado un poco la tasa de empleo, precisamente porque muchos africanos han vuelto a su lugar de origen y han sido ágiles en crear empleo y expectativas de trabajo.

Esta ha sido una de las características de los movimientos migratorios de los 'años de la crisis económica'.

Por último, la llegada de expediciones clandestinas por mar también perdió fuerza y bajó en esos años porque los que venden el negocio ya no tienen el argumento de que en Europa se encuentra trabajo, debido al elevado número de parados que se registra en España y en Europa, sobre todo en los sectores donde los inmigrantes encontraban trabajo hasta entonces.

Además, los inmigrantes que habían logrado salir adelante en España tampoco están en condiciones de enviar dinero a los candidatos de los cayucos, como había sucedido en años anteriores.

\section{Informe de Human Rights Watch en 2010}

Simona Troller, investigadora de la División de Derechos del Niño de la organización internacional Human RightsWatch y responsable del informe "En la trampa de la migración: Menores extranjeros no acompañados en Europa"3 afirma que los menores extranjeros no acompañados "representan una fracción minúscula de todos los migrantes que entran en 
Europa y los gobiernos son incapaces de ofrecer datos fiables". Añade Simona Troller: "No es sorprendente que estos niños se hayan convertido en principal preocupación regional, entre otras razones, porque se consideran una carga para los recursos".

Destaca Simona Troller que la legislación vigente en 2009 en la UE no se ocupa de las necesidades de los menores que no presentan nunca una solicitud de asilo. La investigadora de HRW insiste en que la UE "debe asegurarse de que sus políticas y acciones estén verdaderamente fundadas en los derechos humanos y, por encima de todo, basar su trato a estos menores en su condición de niños y no de migrantes".

El informe de Human RightsWatch denuncia que, a pesar de que todos los gobiernos europeos han firmado la Convención sobre los Derechos del Niño, el principal tratado de las Naciones Unidas para la protección de los menores, en la práctica considera a los menores primero migrantes y después niños. En su opinión, "con demasiada frecuencia, las autoridades recurren primero a las leyes de inmigración y después a las leyes de protección del menor, lo que tiene consecuencias directas y terribles para los niños".

Simona Troller denuncia el maltrato que se da a los menores extranjeros en algunos países europeos:

Francia. Representa uno de los peores ejemplos de lo que ocurre cuando se trata sobre todo como migrantes irregulares a los menores extranjeros no acompañados. Mantiene zonas extraterritoriales, la más amplia es la del aeropuerto Roissy Charles de Gaulle, cercano a París, una zona de tránsito, "un limbo" donde se mantiene durante un tiempo a los menores como si no hubieran entrado al país. Los niños están aislados y sometidos a un régimen jurídico diferente, con el objetivo de expulsarlos cuanto antes. HRW denuncia que el 30\% del millar de niños que pasan cada año por allí fueron expulsados "sin que se registrara lo que había pasado con ellos". La ley francesa dispone que cada niño migrante no acompañado que llegue al aeropuerto esté representado por un tutor. Sin embargo, el papel de estos tutores puede ser redundante. El hecho de que un tutor "llegue demasiado tarde" para encontrarse con el niño no impide a las autoridades francesas deportar al menor. Sólo en 2008, el 30\% de los menores nunca se reunió con su tutor.

Reino Unido. Según HRW, "se criticó durante años a Reino Unido por excluir a los niños migrantes del pleno disfrute de los derechos recogidos en la Convención de Derechos del Niño debido a su condición de migrantes, hasta que retiró sus reservas en 2008, una decisión que anunció días antes de la fecha prevista para que las Naciones Unidas examinara su respeto por los derechos del niño".

Alemania. Mantiene una declaración similar a la francesa, que fue presentada por el Gobierno federal en 1990. HRW critica su postura, porque, "aunque Alemania afirma que no tiene 
objeción para retirar la declaración, el Gobierno federal alega carecer de autoridad para hacerlo, a pesar de las peticiones explícitas del Parlamento, porque, según dice, varios de los 16 estados alemanes sí tienen objeciones. Independientemente de lo que diga, hay otros indicios de que el propio gobierno tiene reticencias para acabar con la discriminación contra los niños migrantes: por ejemplo, afirma que retirar la reserva podría suponer un efecto llamada para la llegada de una gran cantidad de niños migrantes con un coste imprevisible". La organización internacional insiste en que la declaración sigue teniendo graves consecuencias para los menores no acompañados que solicitan asilo en Alemania.

Grecia. Este país es el criticado con más dureza por HRW. "Quizá el régimen jurídico más terrible para los menores considerados migrantes irregulares sea el de Grecia, uno de los principales puntos de entrada de migrantes a Europa", señala el informe de Simona Troller. Denuncia que en ese país "los niños pasan meses en centros de detención -con frecuencia compartiendo celdas con adultos- en condiciones que el organismo de derechos humanos europeo consideró inaceptables. Una vez que quedan en libertad les entregan una orden para que salgan del país. Si no lo hacen, pueden encontrarse de nuevo recluidos”. Precisa que Grecia no dispone más que de 300 plazas en los centros de acogida, que están llenos, para el número estimado de un millar de niños que llegan cada año. Además, este informe indica que los funcionarios de policía griegos señalaron a HRW que no pueden poner en libertad a los menores migrantes detenidos porque no se dispone de otro alojamiento para ellos.

En este informe, junto a los detalles que se exponen de estos países europeos figura el trato, la acogida y los recursos que se destinan a los niños de los cayucos. Troller precisa:

Islas Canarias. España. El Gobierno central de España "escurre el bulto", respecto a los menores extranjeros, asegura el informe de HRW, donde se pone de manifiesto que el hecho de que se apliquen dos tipos de leyes a los menores extranjeros no acompañados implica que al menos dos organismos oficiales sean responsables de ellos, pero esto no se materializa en el doble de asistencia y protección, sino que, la realidad, como sucede en España, es que la atención a los niños se "escurre" a través de las grietas burocráticas. En España, el Ministerio de Asuntos Sociales y el de Interior o Inmigración tienen estrategias diferentes.

Lo que está claro es que, en virtud del derecho internacional, el Gobierno central tiene la obligación de que todos los niños, dentro de su territorio nacional, puedan disfrutar de sus derechos. Y, cuando se transfiere la responsabilidad a las regiones o comunidades (como es el caso de España), las autoridades centrales pueden "escurrir el bulto" detrás de los mecanismos institucionales.

El informe de HRW es contundente en este sentido: "Las islas canarias, que por circunstancias geográficas es el primer punto de desembarco de los migrantes procedentes de África Occidental, Marruecos y el Sahara Occidental, vio como un millar de menores extranjeros no acompañados llegaban a sus costas en 2006. Se apresuró a establecer centros de emergencia 
en naves industriales y reabrió un centro de reforma, previamente cerrado, para albergar a varios centenares de niños. A continuación reclamó al Gobierno central que acogiera o redistribuyera a todos los menores, menos a 300, la capacidad máxima declarada por el Gobierno de las Islas. El Gobierno central organizó y costeó el traslado de algunos niños a otras regiones, pero las llegadas continuas hicieron que se mantuvieran las cifras en Canarias y muy pocas otras regiones se ofrecieron para acoger a niños. Mientras Madrid retiraba gradualmente su asistencia, los centros de emergencia temporales y en condiciones por debajo de la norma, se convirtieron en la residencia permanente de los niños. Incluso después de que Human RightsWatch presentara a Madrid sus observaciones de casos de maltrato y el riesgo continuado para los menores en estos centros, el Gobierno central sostuvo que no podía hacer nada ante la situación. El Gobierno canario ofreció una respuesta similar, señalando que estos centros se cerrarían en cuanto el Gobierno central aceptara hacerse cargo de los niños. La pelota siguió pasándose de uno a otro mientras los niños seguían desprotegidos".

Así informa HRW de la situación. Pero, en la realidad, los niños estaban bien atendidos en Canarias, aunque no en las instalaciones más óptimas ni en el número adecuado para lograr una educación personalizada. Sin embargo, a pesar de ser cientos los niños africanos que conviven los siete días de la semana, durante meses y meses, no se han producido sucesos negativos, ni revueltas, ni hechos delictivos dignos de destacar como problemáticos, salvo episodios aislados, en los que ha tenido que intervenir la Guardia Civil, siempre motivados por menores de origen magrebí, en los que se ha detectado que están acostumbrados a esnifar pegamento, y esto ha ocasionado que se revelaran ante algunas normas impuestas por los educadores. Estos hechos se han saldado con el ingreso del menor en un centro cerrado de medidas judiciales.

También UNICEF exige tratar a los menores extranjeros como niños y no como inmigrantes 4 y exige al Estado español "acabar con la descoordinación entre las comunidades autónomas y las instituciones de asistencia para garantizar que se respeten sus derechos y estén bien atendidos". El informe de UNICEF y el Consejo General de la Abogacía Española (CGAE), elaborado en enero de 2010, analiza la situación de los más de 6.500 menores no acompañados que viven en España en el año 2009. Estas instituciones exigen "la puesta en marcha del Registro Nacional de Menores Extranjeros no Acompañados, previsto legalmente" y lo consideran "urgente", porque hasta la fecha sólo existen cifras globales.

Además, subraya la importancia de garantizar la tutela efectiva de estos menores, la "concesión inmediata" del permiso de residencia y un mejor control de los recursos disponibles para su educación e integración.

\footnotetext{
${ }^{4}$ Informe "Ni ilegales ni invisibles", elaborado por UNICEF y el Consejo General de la Abogacía Española: www.unicef.es/contenidos/1002/informe_infancia_inmigrante_UNICEF_CGAE_2009.pdf
} 
El coordinador del informe, Pascual Aguelo, presidente de la subcomisión de Extranjería del CGAE, manifestó en la presentación del documento que los recursos destinados a las políticas de atención e integración de los niños de los cayucos "son muy altos, pero no tienen los frutos que debieran por culpa de la descoordinación entre organismos y administraciones".

Este informe aparece mientras el Gobierno español debate la reforma de la Ley de Extranjería. Los autores del estudio reconocen que la nueva ley que se prepara "sigue primando la repatriación de estos niños" y, en su opinión, “de seguir así, el artículo 35 de la Ley quedará en papel mojado". Los autores recalcan que dar prioridad a las repatriaciones en los casos de menores que han llegado a España por una entrada ilegal constituye una "política ineficaz" y supone "quitarse el problema de en medio".

Las noticias relacionadas con la inmigración y su contexto tienen generalmente un carácter negativo (Cardoso, 2001). ¿Así somos de racistas, de xenófobos, de excluyentes, de intolerantes con los inmigrantes?, se preguntaba la gente de bien:http://www.ull.es/publicaciones/latina/2001/latina41mav/52cardoso.htm.

Con el paso de los años no ha cambiado mucho esta percepción, la que se refleja en los medios de comunicación.

Muchos son los estudios que han analizado la imagen de los inmigrantes en los medios, así como las relaciones entre los componentes emocionales y motivacionales en la producción de los discursos sobre las cuestiones identitarias o sobre la interculturalidad (Benítez, 2010) y la relación social y familiar en la configuración de los proyectos migratorios de los jóvenes marroquíes (Benítez, 2011), lo cual supone la coincidencia de las redes migratorias con los vínculos familiares.

El material gráfico que acompaña a las noticias sobre inmigración tiene verdadera importancia, sobre todo, cuando las imágenes son informativas. La fotografía colabora en la construcción del discurso periodístico de manera tan importante como los textos: http://www.ull.es/publicaciones/latina/08/34 79154 fotoperiodismo/Alberto Ardevol.h $\underline{\mathrm{tml}}$

Dentro del período de estudio se produjo la agresión a un inmigrante en un supermercado grancanario. El vídeo, difundido por el diario Canarias7, de Las Palmas (http://www.canarias7.es/multimedia/video.cfm?id=7693) muestra las imágenes grabadas por las cámaras de seguridad del local el 8 de enero de 2011. En ellas se puede ver a un policía local de Mogán golpeando a un ciudadano senegalés. Esta es una de las pruebas de la defensa del africano que inició acciones legales contra su agresor. En el periódico, el policía está identificado con su número de agente y el senegalés aparece con su nombre y apellido. La controversia viene porque, en el proceso judicial, el inmigrante acusa a dos agentes policiales de lesiones, mientras que los policías aseguran que fue el senegalés quien les agredió. La cámara de seguridad solo muestra los golpes que propicia uno de los policías al inmigrante. 


\section{Características metodológicas}

Este artículo emplea un análisis cualitativo de la legislación europea y analiza las palabras clave en los citados documentos sobre la migración infantil, donde aparecen de forma repetitiva los términos:

1. Problema.

2. Devolución.

3. Expulsión.

4. Retorno.

5. Derechos del niño.

6. Migración irregular.

7. Estadísticas.

8. Cooperación con países terceros.

9. Frontex.

El objetivo es examinar si la terminología que se emplea en las leyes europeas al hablar de la migración infantil coincide o se asemeja con el punto de vista que se tiene en África de este fenómeno y con el que se recoge en las informaciones estudiadas.

La originalidad del trabajo consiste en que hemos tenido acceso a un centenar de testimonios de jóvenes africanos, tanto en el país de acogida (España), como en origen (Senegal o Marruecos), que ayudan a contrastar 'las dos caras de la misma moneda' de la migración infantil. Entendemos que la metodología cualitativa ayuda en este análisis.

Todos los términos que se emplean en las directivas europeas dan a entender que la entrada de jóvenes africanos en cualquiera de los países de la UE es un problema generalizado, porque, una vez que han conseguido instalarse en cualquiera de ellos y han obtenido el permiso de residencia, tienen libertad de movimiento en el entorno Schengen.

Entre los términos más frecuentes figuran los que se han detallado anteriormente, que aluden a una situación conflictiva que es necesario resolver.

En cambio, analizando las historias de cada uno de los jóvenes de los cayucos se comprueba que la migración infantil es un drama. Máxime cuando se trata de niños sin compañía y, en ocasiones, huyendo de una muerte segura, como es el caso de los niños soldado.

La UE sí reconoce que el desafío que plantean los menores no acompañados es cada vez mayor, basándose en las estadísticas (Aubarell, G. y Zapata-Barreto, R. (2004): "Numerosos nacionales de terceros países o personas apátridas menores de 18 años llegan al territorio de la 
UE no acompañados por un adulto responsable, o dejan de estar acompañados una vez que han entrado en el territorio de la UE"5.

Fue en el año 1999 cuando comienza a ser frecuente que entre los ocupantes de las pateras se encuentren niños africanos que viajan solos. Si el fenómeno de la inmigración clandestina, referida a los adultos, desbordó todas las previsiones en los siguientes 10 años, la constante llegada de niños en pateras o cayucos, sin compañía de familiares, provocó desconcierto y asombro en la población y entre los partidos políticos, que no habían previsto lo que se avecinaba. Los hechos hicieron reflexionar a la sociedad y, con mucho retraso, a los gobiernos español y europeo.

De la misma forma que con el resto de los inmigrantes de las pateras o cayucos, el tratamiento de los menores inmigrantes no acompañados que empiezan a llegar a países europeos -entre ellos España- por una entrada clandestina, a principios del siglo XXI era resuelto por cada uno de los Estados de forma unilateral ${ }^{6}$.

El continente africano es el gran desconocido. Pasan los años y la UE sigue sin una política común de inmigración, por lo que no le queda más que reconocer que, otro de los inconvenientes que dificultan el estudio de la migración infantil es que cada uno de los Estados miembros lo resuelve 'a su manera'.

Respecto a las solicitudes de asilo, las estadísticas más completas son las recogidas por la Red Europea de Migración, que en 2008 recibió un total de 11.292.En el mundo, más de 70 millones de personas son migrantes forzosos, pero, ¿cuántos de ellos son menores?7

Una de las razones de la migración infantil es escapar de la guerra, como se constata en el caso de los niños soldado (Merino Arribas, Ma A. (2012), una de las mayores tragedias de la sociedad contemporánea.

El Programa de Estocolmo hace hincapié en la prevención de la migración infantil, así como en la protección de los niños que logran llegar solos a territorio europeo y, también incide en ayudar al retorno del menor a su lugar de origen, en el caso de que sea posible.En un solo párrafo aparecen estas ideas: frenar las salidas, protección de los menores que llegan a Europa y retorno a su lugar de origen.

Este último punto, el retorno, es una de las asignaturas pendientes, porque se trata de una cuestión 'multidimensional' que solo se podrá resolver a largo plazo. En este sentido, se echa en falta que la normativa europea no aluda suficientemente al principio de no devolución.

${ }^{5}$ Comisión Europea. Bruselas, 6.5.2010COM (2010)213 final.

${ }^{6}$ Náufragos con GPS. Testimonios de niños de los cayucos, página 17 
En cambio, la UE sigue hablando de la repatriación del menor, como una de las opciones, cuando este término es inadecuado, porque solo se aplica para los adultos y en el caso de los niños se denomina reagrupación familiar. Además, tampoco es una medida óptima, como ya hemos explicado anteriormente.

Las razones por las que estos jóvenes no quieren decir cuál es su lugar de origen son variadas:

a). Volver sin nada sería una vergüenza.

b). Aunque se hayan marchado sin el consentimiento familiar no serían bien admitidos antes de lograr su objetivo.

c) Salen de su zona natal porque allí no encuentran el futuro que anhelan.

d). Se han comprometido, a veces solo con ellos mismos, a conseguir medios para ayudar a los suyos.

e). Han atravesado tantos peligros para llegar a Europa, que no quieren ni pensar en repetir la experiencia.

f). Son niños en Europa, porque no han alcanzado los 18 años, pero ese parámetro no les convierte en desprotegidos en África, donde el trabajo infantil está al alcance de todos y la supervivencia en solitario también se contempla para los niños.

Los testimonios de los menores que han llegado en pateras o cayucos son elocuentes. Si en algún momento de dificultad, en el trayecto o en la sociedad de acogida, se les ha pasado por la cabeza que quieren regresar, les basta observar y comprueban cómo se vive en Europa para cambiar de opinión. Confiesan que no les atrae solo el aparente estado del bienestar, sino que Europa también promete un futuro mejor para ellos.

Respecto a la prevención de la migración infantil, para la UE es prioritario promover campañas de formación en los países de origen. Esta iniciativa es difícil ponerla en práctica mientras siga la inestabilidad política y la falta de gobiernos democráticos que se preocupen realmente por su pueblo. Está claro que hay que formar, en primer lugar, a los que tienen que ser garantes de los derechos de la infancia, como pueden ser los responsables gubernamentales o los agentes policiales y todas las autoridades relacionadas de una u otra forma con la educación de la infancia.

Por parte de la UE también se proponen campañas de información y sensibilización, dirigidas a los menores de edad, con el fin de explicarles los riesgos que corren por emigrar de forma clandestina. Es cierto que los testimonios sinceros de los chicos de los cayucos dejan claro que ignoraban los peligros a los que se enfrentaban y que, de haber sabido en qué consistía el trayecto en el cayuco, y todos los prolegómenos, no lo hubieran intentado. Lo que ocurre, es que la inmigración clandestina es un triste negocio, que no se ha erradicado, a pesar de que los medios de comunicación ya han difundido ampliamente estos riesgos y también se conocen en el vecino continente. 
En cuanto a la iniciativa de la UE de buscar a los menores alternativas de formación o trabajo en su lugar de origen, las dificultades se multiplican.

El estudio comparativo de la UE, de 2010, deja claras las deficiencias de las políticas de acogida, repatriación y acuerdos para la integración de los menores extranjeros no acompañados, así como la falta de datos reales. Es un documento que recoge estas cuestiones en 22 países europeos (Alemania, Austria, Bélgica, República Checa, República Eslovaca, Eslovenia, España, Estonia, Finlandia, Francia, Grecia, Hungría, Irlanda, Italia, Letonia, Lituania, Malta, Países Bajos, Polonia, Portugal, Reino Unido y Suecia).

Otro documento europeo más reciente, de octubre de 2012, 'Unprotected unaccompanied children in Europe' pone de manifiesto la necesidad de encontrar "soluciones duraderas" en las políticas que hagan referencia a los menores extranjeros no acompañados.

Respecto a las informaciones publicadas sobre la inmigración infantil cabe destacar la importancia de hacerlo dentro de los parámetros del periodismo de precisión (Dallanhol, Heloísa, 2000), http://www.revistalatinacs.org/aa2000kil/x33se/62helo.htm y, si es posible, que las noticias sean elaboradas por periodistas especializados en esta materia. De lo contrario, se puede caer en estereotipos, con el riesgo de presentar los hechos sin el contexto y la profundidad que requiere, en concreto, la migración infantil.

Es preciso realizar una apreciación. Las informaciones que publican los periodistas pueden ser antagónicas a los editoriales del medio en el que trabajan (Rodríguez, Rodrigo F. 2010): http://www.revistalatinacs.org/10/art2/895 ULL/17 Rodrigo.html. El caso que se analiza hace referencia a una situación sin precedentes: el Parlamento de Canarias aprobó el 24 de septiembre de 2008 una declaración institucional de condena al periódico El Día, editado en Tenerife, Islas Canarias (España) por las "ideas xenófobas" que reiteradamente aparecen en sus editoriales. El texto de la denuncia se puede consultar en http://media.epi.es/www.laprovincia.com/media/documentos/2008-08-24 DOC 2008-04-

24220827 denuncia racismo ben magec.pdf.

Los jóvenes se asocian "para ser familia”. Lass Kemso Sang es un joven africano que llegó a Canarias en cayuco en agosto el año 2008. Su expedición alcanzó la isla de El Hierro. Era el final de un largo viaje y el principio de una vida desconocida. Había transcurrido un año desde que abandonó el hogar familiar, en una aldea de Guinea Conakry y recorrió miles de kilómetros hasta llegar a Mauritania, donde se embarcó en una expedición clandestina con destino a Europa. Se fue de su casa sin decir nada. Es el segundo de seis hermanos, pero el varón mayor, el que carga con la responsabilidad de sacar adelante a la familia, según su cultura.

Lass pasó dieciocho meses en un centro de menores de emergencia del Gobierno canario de Tenerife, junto con centenares de chicos, que no tardaron en darse cuenta de que era despierto 
por naturaleza y con cualidades extraordinarias. Meses más tarde es elegido por unanimidad como presidente de la asociación que crean ellos mismos.

Igual que otros muchos casos, cuando se determinó su mayoría de edad, Lass abandonó el centro y viajó hasta Murcia con la ilusión de encontrar un empleo que le permitiera legalizar su situación en España, mediante un contrato de trabajo de un año. Estos chicos salen de los recintos de acogida con una tarjeta de residencia que caduca a los tres meses. En este tiempo, su prioridad es encontrar el ansiado empleo. Algunos jóvenes, por razones muy especiales, consiguen un permiso de residencia de un año o más.El joven guineano no consigue trabajo en ninguna comunidad peninsular y se encuentra durmiendo en un banco de la calle, al raso. Cuando se lo cuenta a sus amigos tinerfeños recibe la oferta de regresar a la isla.

A finales del año 2010 se van cerrando los centros de emergencia canarios, porque los niños de los cayucos van cumpliendo los 18 años a decenas. Los que deciden quedarse en Canarias toman la iniciativa de asociarse, con el fin de sentirse unidos y también para ayudarse a la hora de resolver su situación burocrática. Así nace la Asociación de Jóvenes Africanos, que tiene como presidente a Lass Kemso Sang.

Los africanos que han llegado al Archipiélago en cayuco y han estado meses o años acogidos por el Gobierno canario ven "naufragar sus sueños" cuando al cumplir la mayoría de edad abandonan los recintos de acogida. Ahora tienen 18 años recién cumplidos en España, pero la experiencia que narran indica que nacieron hace bastante más tiempo en África. Casi todos tienen en su poder un pasaporte en vigor. No lo traían en el cayuco, pero han logrado que la familia se lo envíe desde su país natal.

\section{Conclusiones}

1. La UE todavía considera la migración infantil desde el punto de vista de 'un control de las salidas', para evitar que jóvenes africanos entren en Europa. Aún sabiendo que es imposible cerrar las fronteras a las migraciones, tal y como argumenta, Perspectives on migration flows in Asia and Europe (Perspectivas sobre flujos migratorios en Asia y Europa), que tiene a Antonio Marquina como coautor.: http://elpais.com/diario/2012/01/23/ultima/1327273202 850215.html. Al mismo tiempo, la Comisión europea reconoce que el control fronterizo no es suficiente para solucionar los problemas que plantea la migración de menores no acompañados y la CE propone el proyecto de vida. Se entiende con esta iniciativa que se ponen en marcha planes individualizados, para cada uno de los niños extranjeros que han entrado en el territorio español sin compañía, con el fin de dibujar perspectivas de futuro personalizadas, teniendo en cuenta su origen, su formación y todas las circunstancias que rodean a cada persona. Interesa destacar que la CE señala que el proyecto de vida puede llevarse a cabo tanto en el país de origen del menor como en el de acogida. Entre las condiciones marcadas por Europa para poder sacar adelante esta iniciativa se detallan algunas que chocan de frente con la falta de legislación en la mayoría de los países africanos origen de la migración infantil, como el respeto a los 
derechos humanos o una normativa antidiscriminación. En la prensa no hemos encontrado ninguna información al respecto.

2. En la normativa europea no se alude suficientemente al principio de no devolución. El 3 de junio de 2010, El País publicó "La UE financiará la devolución de menores inmigrantes". En 2010, la UE aprobó un texto legislativo para que los 27 Estados miembros establecieran criterios homogéneos sobre la migración infantil, donde se incluía la localización de su familia y el regreso a su zona natal. En el caso de que no fuera localizada la familia del menor sería trasladado a un centro de acogida en su país de origen. Nuevamente, estas iniciativas plasmadas en acuerdos legislativos no se pueden llevar a la práctica. Aunque es fácil localizar a las familias de los menores, puesto que ellos mantienen con ellas contacto telefónico periódico, los progenitores son los primeros que no aceptan el regreso del hijo al hogar, puesto que tienen puestas sus esperanzas de futuro en el joven que ha emigrado. Por este motivo, a pesar de ser público y notorio que los menores mantienen conversaciones con sus padres, se niegan a facilitar su contacto.

3. Las iniciativas que proponen los legisladores de la UE, como campañas de concienciación en origen o crear ámbitos educativos y profesionales no se pueden llevar a cabo a corto plazo, porque es necesario contar con el apoyo de los gobernantes y de los ciudadanos africanos, con una cultura, unas tradiciones y un régimen de gobierno que no se parece en nada a lo europeo y hace que no exista colaboración activa para desarrollarlas como propone la UE. Este es otro de los escollos con los que choca la cultura y la política occidental con la africana.

4. Los jóvenes africanos que buscan un futuro en Europa desconocen la legislación del mundo occidental y ven fracasadas sus expectativas de trabajo. Esto lleva a que no puedan enviar a África las remesas que desde allí les reclama su familia. Es preciso tener en cuenta que la familia en África no se concibe con en Europa. Debido a la poligamia, la comunidad familiar es muy extensa y, en el vecino continente, se tienen las mismas obligaciones familiares con todos los parientes, incluso lejanos. Los jóvenes de los cayucos reciben llamadas, pidiendo dinero, de familiares muy lejanos, que al enterarse de que están en Europa les reclaman ayuda económica. Una de las frustraciones de estos chicos es tener que explicarles lo que en África no se puede entender.

5. Los menores agradecen la buena acogida en el país de entrada, pero insisten en que necesitan trabajar y poder enviar remesas cuanto antes. Tras su llegada se abre ante sus ojos un 'círculo vicioso' difícil de resolver. No pueden trabajar en Europa mientras sean menores de edad y saben que su permanencia en la UE y su inserción social está ligada a un contrato de trabajo. Por este motivo, $\underline{\text { la inserción social pasa a ser el primer }}$ objetivo de los menores extranjeros no acompañados que llegan en expediciones 
clandestinas. Ante el peligro de la inmediata expulsión de los adultos que entran por esta vía, los que pueden se declaran menores de edad, como una forma de ganar tiempo para conseguir su objetivo final.

6. Tras las entrevistas realizadas, la mayoría de ellos declara que su objetivo final es pasar unos años en Europa, para formarse profesionalmente y después volver a su lugar de origen para elevar el nivel de su zona natal.

\section{Referencias bibliográficas}

- Aierbe, P. (2002). Análisis de prensa 2002. Inmigración, racismo y xenofobia. Donosita: Tercera Prensa S.A.

- Ardevol Abreu, Alberto (2008): La inmigración en la fotografía de prensa de Canarias. Revista Latina de Comunicación Social, $63 . \quad$ La Laguna (Tenerife).http://www.revistalatinacs.org/08/34 79154 fotoperiodismo/Alberto Ardevol. html. DOI:10.4185/RLCS-63-2008-791-409-417.

- Asociación Pro Derechos Humanos de Andalucía. (2010). Informe Derechos Humanos en la Frontera Sur 2009. Sevilla. www.apdha.org.

- Aubarell, G. y Zapata-Barreto, R. (2004). Inmigración y procesos de cambio. Europa y el Mediterráneo en el contexto global. Barcelona. Icaria.

- Benítez Eyzaguirre, Lucía. (2011). La recepción transnacional de la televisión y su relación con las migraciones.Congreso Internacional Sobre Migraciones en Andalucía.

http://migraciones.ugr.es/congreso2011/docs/I CIMA Resumenes.pdf. ISBN 978-84-6940400-3.

-Benítez Eyzaguirre, Lucía. (2010). El imaginario de España en la recepción de la televisión en Marruecos. Actas II Congreso Internacional Estudios Literarios Hispano africanos.http://www.hispanoafricarteliteraturas.com/congreso 2010/html 2010/pdfs/pro grama completo.pdf. ISBN 978-84-693-6513-7.

-Blas, I. y Merino, M.A. (2012). Vuelven los titulares tendenciosos para informar sobre los inmigrantes. Teoría del framing en el análisis informativo. Disponible en formato on line: http://www.revistalatinacs.org/12SLCS/2012 actas/195 Blas.pdf.

-Cardoso Carballo, Juan Manuel (2001): Violencia, inmigración y xenofobia: el periodismo frente a los grandes retos informativos. Revista Latina de Comunicación Social, 41. http://www.ull.es/publicaciones/latina/2001/latina41mav/52cardoso.htm. 
- Dallanhol, H. (2000): "Propuesta de cobertura periodística sobre la inmigración ilegal". Revista Latina de Comunicación Social, $\mathrm{n}^{\circ}$ 33, disponible en: http://www.revistalatinacs.org/aa2000kil/x33se/62helo.htm.

- Igartua, J. J., Muñiz, C. y Cheng, L. (2005): "La inmigración en la prensa española. Aportaciones empíricas y metodológicas desde la teoría del encuadre noticioso". Migraciones, $\mathrm{N}^{\circ} 17$, pp. 143-181.

- Igartua, J. J., Muñiz, C. y Otero, J. A. (2006): El tratamiento informativo de la inmigración en la prensa y la televisión española. Una aproximación empírica desde la Teoría del Framing". Global Media Journal, vol. 3, $\mathrm{n}^{\circ}$ 5, disponible en:http://gmje.mty.itesm.mx/igartua muniz otero.htm..

- López García, B. y Berriane, M. (dir.). (2004). Atlas de la inmigración magrebí en España. Atlas 2004. Madrid: Dirección General de Migraciones/UAM.

- Gobierno de Canarias. Planes de Acción para la Acogida e Integración de Inmigrantes, así como el Refuerzo Educativo. (2008). Decreto 167/2008, de 22 de julio. Consejería de Bienestar Social del Gobierno Canario. Santa Cruz de Tenerife.

- Merino Arribas, Ma A. (2012)Nánfragos con GPS. Los niños de los cayucos.AV Akademikerverlag GmbH \& Co. KG. Alemania.

- Nair, Sami:Y vendrán... Las migraciones en tiempos hostiles. (2006). Barcelona. Editorial Bronce.

- Rodríguez Borges, Rodrigo F. (2010): Discurso xenófobo y fijación de agenda. Un estudio de caso en la prensa de Canarias (España), en Revista Latina de Comunicación Social, 65. La Laguna (Tenerife). Universidad de La Laguna, páginas 222 a 230. http://www.revistalatinacs/10/art2/895 ULL/17 Rodrigo.html. DOI: 104185/RLCS-652010-895-222-230.

- Rodríguez Díaz, Raquel y Mena Montes, Noemí (2008): Opinión Pública y frames: La crisis de los cayucos. Revista Latina de Comunicación Social, 63, páginas 341 a 347. La Laguna (Tenerife): Universidad de

Laguna.http://www.ull.es/publicaciones/latina/08/28 46 Vicalvaro/Raquel_Rodriguez_y Noemi_Mena.html. 


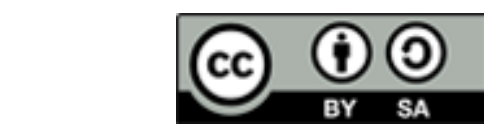

Licencia Creative Commons

Miguel Hernández Communication Journal

mhcj.es

\section{Forma de citar este artículo en las bibliografías}

María-Adoración Merino-Arribas, Ana Baroni-Luengo (2013): “Titulares que reafirman la ineficaz respuesta de la política europea a la migración infantil africana”, en Miguel Hernández Communication Journal, nº4, páginas 67 a 89. Universidad Miguel Hernández, UMH (ElcheAlicante). Recuperado el _ de de 20

de: http: $/ /$ mhcj.es $/$ index.php?journal=mhcj\&page $=$ article\&op=view\&path $\% 5 \mathrm{~B} \% 5 \mathrm{D}=4$ 